\title{
Staff Nurses Perception Toward Organizational Culture and Its Relation to Innovative Work Behavior at Critical Care Units
}

\author{
Fawzia Farouk Kamel ${ }^{1}$, Mervat Abd Elmonem Aref ${ }^{2}$ \\ ${ }^{1}$ Nursing Administration, Benha University, Benha, Egypt \\ ${ }^{2}$ Nursing Administration, Damanhur University, Damanhur, Egypt
}

Email address:

fawzia_elgazar88@yahoo.com (F. F. Kamel),noeman_mervat@yahoo.com (M. A. E. Aref)

\section{To cite this article:}

Fawzia Farouk Kamel, Mervat Abd Elmonem Aref. Staff Nurses Perception Toward Organizational Culture and Its Relation to Innovative Work Behavior at Critical Care Units. American Journal of Nursing Science. Vol. 6, No. 3, 2017, pp. 251-260. doi: 10.11648/j.ajns.20170603.23

Received: February 22, 2017; Accepted: March 15, 2017; Published: May 22, 2017

\begin{abstract}
Background: Health care organization culture can influenced by its ability to manage human resources and has a strong impact on its performance. Aim: the study aimed to assess staff nurses perception toward organizational culture and its relation to their innovative work behavior at critical care units. Setting: The study was conducted in critical care units at Benha University Hospital. Research design: descriptive correlation design was utilized to conduct this study. Sample: Convenience sample consisted of 76 nurses who worked at the previously mentioned setting. Tools: Two tools were used for data collection; (a) organizational culture assessment questionnaire and (b) Innovative work behavior scale. Results: the study showed that, the highest mean score of nurses perception regarding organizational culture was related to organizational learning $(2.51 \pm 19.15)$, while the lowest mean score was related to creating change (12.10 \pm 3.26 ). Also, the highest mean score of innovative work behavior were related to idea championing and idea implementation (8.46 \pm 1.91 and 12.30 \pm 2.76$)$. Conclusion: more than half of staff nurses had positive perception regarding organizational culture, half of staff nurses had high innovative work behavior and there is a significant correlation between staff nurses perception regard organization culture and their innovative work behavior. Recommendations: it recommended that, enhance nurses organizational learning through designated in-service educational programs, reduce staff nurses resistance to change through communication and support innovation as a job requirement.
\end{abstract}

Keywords: Critical Care Units, Innovative Work Behavior, Staff Nurses, Organizational Culture

\section{Introduction}

Organizations are characterizing forums where individuals with different backgrounds, abilities, personalities and behaviors wok together as a cooperative unit to achieve certain objectives [1]. Culture is behavioral pattern which governs the way of nurses interacts with others. It helps in distinguishing one nurse from the other [2]. Each organization have a distinct culture that found in practices, values, beliefs, expectations, assumptions, and collective memory which tend to strongly resist to change. It emphasizes on social dynamic characteristic of organizations and determines the organization strategy and performance so it is an important factor of success or failure of organization.
The organization culture consisted of several factors including internal communication, work balance, leadership style professional growth, employee satisfaction, reward system, and organization performance. When any of these factors are compromised, it can effect negatively on organization productivity and profits $[3,4]$.

According to Denison, 2011 organizational culture classified into two focuses. Internal focus consist of six areas: empowerment; share employees in their work, team orientation; encourage cooperation of different parts in the organization, capability development; capabilities of people for competitive, core values; consistent and clear set of values that governs the performance, agreements; reach consensus on difficult issues, and coordination \& integration; 
coordinate plans across different parts of the organization. The external focus of the organizational culture includes six areas; creating change; the work are done in flexible and easy to change, customer focus; customer input is directly influences decisions, organizational learning; learning is an important objective in day-to-day work, strategic direction \& intent; clear strategy for the future, goals \& objectives; there is agreement about goals, and vision; leaders have a longterm dreams [5].

Health care organization culture influenced by its ability to manage human resources and satisfy patients. In addition to health care organizations that characterize by constructive cultures encouraging positive interpersonal relationships as well as value self-actualization and achievement oriented [6].

In the rapid changing environment, organizations are facing greater challenges, and need to promote innovative behaviors for nurses to deliver their services, to stay competitive, and lead the change process itself. In order to accomplish their tasks successfully, organizations render support to their nurses to innovate their process, methods, and operations [7].

Innovation is the change related with the new creation and adaptation of ideas. The creativity occur with new ideas depends on the organization management as well as individuals generating new ideas. The ability to create innovative solutions dependent on the knowledge, and experience of nurses to solve the novel problem [8].

Critical care nurses practice in settings where patients require complex assessments and interventions. Nurses lead inter-professional teams in creating safe, respectful, healing, and caring environments where: leadership encourages and supports lifelong learning and professional growth, individual talents and resources are optimized, innovation, creativity, and clinical inquiry are recognized and valued. such environments recognize and support the authority, autonomy, and accountability of nursing and support optimal patient outcomes [9].

Innovative work behavior is not part of the nurses job. It is extra-role behavior which refers to open behavior that is not specified in the job description for attempts to organization benefit [10]. Nurses' innovative work behavior is essential in management such as suggestion programs and continuous improvement [11].

According to Noor \& Dzulkifli (2013) and Chombunchoo (2016) innovative work behavior include three stages: idea generation, coalition building and implementation. In the idea generation, innovation is started by problem identification, defining problem and finding a solution to solve the problem. Finding the solution based on a new concept or a new arrangement of existing concepts. In the coalition building, the innovator looks for support his ideas $[12,13]$.

The innovator need to support his idea because the innovation goes along with changes and resistance to change. The promoter of the innovation will have to create commitment for the innovation and often build coalitions [14]. In the idea implementation, the innovation has to be implemented. The implementation needs an approach of perseverance. For the different phases to create innovative solutions the nurses need different kind of attitude and skills [13].

According to Dul and Ceylan (2010) organizational support the innovation through two aspects: perceived innovation encouragement and adequate supply of resources for innovation. The first refers to the individual's perceptions of the degree of innovation encouragement by the organization. It includes encouragement of risk-taking and of idea generation, supportive evaluation of new ideas, valuing of innovation throughout the whole organization. Also, encouragement for innovation is also reflected in rewards and recognition for innovation and flow collaborative idea across the whole organization. The second aspect relates to organizations resources that support innovation includes adequate equipment and facilities supply, and time for innovation [15].

\subsection{Significant of the Study}

Organizational culture has the potential to enhance organizational performance, nurses job satisfaction, and the sense of certainty about problem solving. The critical role of culture can improve the ability of an organization members to innovate. Also, possession of positive cultural characteristics provides the organization with the necessary ingredients to solve problem with creativity [16]. So, the present study will assist in developing understanding about the role of organizational culture elements in supporting the nurses' innovative work behavior. Organizational culture can encourage or discourage a variety of behaviors and decisions, including those related to innovation. Thus it is important to use the organization culture to mobilize and motivate nurses to be creative and innovative. Also the study of innovative work behavior would help in generating proactive attitude towards novel technologies in the health care, developing new policies. Thereby, motivating nurses to raise new ideas and to develop their creativity at part with national and international requirements $[9,16]$.

\subsection{Aim of the Study}

This study aims at assessing staff nurses perception toward organizational culture and its relation to innovative work behavior at critical care units.

\subsection{Questions of the Study}

1. What is the staff nurses perception toward organizational culture?

2. What is the level of innovative work behavior among staff nurses?

3. Is there a relationship between staff nurses perception toward organizational culture and their innovative work behavior?

\section{Methodology}

\subsection{Research Design}

Descriptive correlation design will be used to carry out this 
study.

\subsection{Setting}

The study was conducted at Benha University Hospital in three critical care units; (intensive care unit (ICU), Coronary care unit (CCU) and Cardiothoracic care unit).

\subsection{Subjects}

Convenience sample consisted of 76 staff nurses; 47 of them working at intensive care unit (ICU), 18 staff nurses working at coronary care unit (CCU) and 11 staff nurses working at cardiothoracic care unit, subject was recruited according to the following inclusion criteria; staff nurses had not less than one-year experience in their working place at the time of study.

\subsection{Tools of Data Collection}

\subsubsection{Two Tools Were Used to Collect Data}

a- Organzational culture assessment questionnaire: it was developed by (Denison, 2011) to assess saff nurses perception toward organzational culture. It included 60 items subdivided under two main subscales internal focus contains 30 items divided into 6 elements (empowerment 5 items, team orientation 5 items, capability development 5 items, core values 5 items, agreements 5 items and coordination \& integration 5 items) and external focus contains 30 items divided into 6 elements (creating change 5 items, patient focus 5 items, organizational learning 5 items, strategic direction \& intent 5 items and goals \& objectives 5 items, and vision 5items) [5].

\subsubsection{Scoring System}

The answers were measured by likert scale with five points. Ranging from; $1=$ strongly disagree to $5=$ strongly agree. The scoring levels were arranged as follow; less than $60 \%$ for negative perception, from $60 \%$ to less than $75 \%$ for neutral perception and $\geq 75 \%$ for positive perception.

\subsubsection{B - Innovative Work Behavior Scale}

It was developed by (De Jong, 2007) to assess innovative work behavior. It consisted of 11 items divided to four elements: idea exploration (3 items), idea generation (3 items), idea championing ( 2 items) and idea implementation (3 items) [17].

\subsubsection{Scoring System}

The answers were measured by likert scale with five points, ranging from $1=$ never to $5=$ always. The scoring levels were arranged as follow; less than $65 \%$ for low innovative work behavior, from $65 \%$ to less than $75 \%$ for moderate innovative work behavior and $\geq 75 \%$ for high innovative work behavior.

\subsubsection{Validity of the Tools}

The tools were tested for content validity by jury of five staff members of nursing administration in different faculties of nursing. All of their comments were taken into consideration; some items were re-phrased.

\subsubsection{Reliability of the Tools}

Reliability of the tools were conducted to determine the internal consistency and homogeneity of the used tools by Cronbach's Alpha test. The reliability of organzational culture questionnaire was of 0.98 and The reliability of Innovative work behavior scale was 0.85 .

\subsection{Data Collection Methods}

1. A review of recent national and international related literature using journals, periodicals, textbooks, internet, and theoretical knowledge of the various aspects concerning the topic of the study.

2. Preparation of data collection tools was carried out over a period of two months from beginning of February 2016 to end of March 2016.

3. The investigators prepared the tools and translated them into Arabic form to become ready for use.

4. Once tools became ready, they tested for content validity by jury of five staff members of nursing administration in different faculties of nursing. The validity of the tools aimed to judge its clarity, comprehensiveness, relevance, and accuracy. Modifications and rephrasing of some statements were done based on experts opinions. Also the reliability of the tools were conducted to determine the internal consistency and homogeneity of the used tools by Cronbach's Alpha test and pilot study was carried out on April 2016 and conducted on about $10 \%$ of total sample ( 8 nurses). The aim of pilot study was to examine the sequence of items, feasibility, practicability and applicability of the tools, clarity of the language and for estimating the time needed to fill it. The tool was finalized based on the result of the pilot study. The pilot study was included in the main sample.

5. Data collection took about one month (from the beginning to the end of may 2016).

6 . The investigator distributed the data collection forms with instructions about how to fill them.

7. The time required to fill the questionnaires sheet was from 20 to 25 minutes. The filled forms were collected in time and revised to check their completeness to avoid any missing data. The average number of gathering questionnaires was between 4-5 per day and for 4-5 days/week.

Ethical considerations:

1. An official letters obtained from the dean of faculty of nursing that sent to the directors of the hospital explaining the aim of the study.

2 . The investigators meet with unit managers to explain the aim of the study to gain their acceptance, participation, as well as organizing and arranging the nurse's participation according to type of work and work load of each department.

3. Then the investigators started by introducing themselves to each group of nurses and gave 
explanations about the purpose of the study and getting agreement of nurses to participate in the research.

4. At the interview with nurses to collect data they informed about the purpose and benefits of the study, and they were informed that their participation is voluntary on that they have the right to share or refuse to participate in the study at any time without giving any reason.

5. In addition, confidentiality and anonymity of the subjects were assured through coding of all data.

\subsection{Statistical Design}

Data entry was done using Excel computer software package, while statistical analysis was done using statistical package for the social sciences (SPSS version 20). Data were presented using descriptive statistics as number, frequency mean, and standard deviation, and pearson correlation coefficients (r). A significance level value was considered when $\mathrm{p}$-value $\leq 0.05$ and a highly significance level was considered when $\mathrm{p}$-value $\leq 0.001$, while $\mathrm{p}$ - value $>0.05$ indicates non- significance results.

\section{Results}

1. Table 1, illustrates agreements of the staff nurses regard empowerment as categories of organization culture, It showed that the highest percentage of staff nurses agreement $(73.7 \%)$ was related to nurse believes that he or she can have a positive impact.

2. Table 2, revealed agreements of the staff nurses regarding creating change as categories of organization culture, It showed that about two thirds of staff nurses $(63.2 \%)$ were disagree that nurses respond well to competitors and other changes in the work environment. Also, more than half of staff nurses (59.2\% and 52.6\%) reported not sure respond related to new and improved ways to do work are continually adopted and attempts to create change seldom meet with resistance respectively.

3. Table 3, demonstrated agreements of the staff nurses regard organizational learning as categories of organization culture, it revealed that highest percentage of staff nurses agreements (65.8\% and 61.8\%) was related to nurses view failure as an opportunity for learning and improvement and learning is an important objective in their day-to-day work respectively.

4. Table 4, revealed that the highest mean score of nurses perception regard organizational culture was related to organizational learning (19.15 \pm 2.51$)$, while the lowest mean score was related to creating change

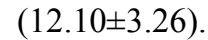

5. Figure 1, revealed that, more than half of staff nurses $(60.5 \%)$ had positive perception regarding organizational culture.

6. Table 5, illustrates distribution of the staff nurses regard innovative work behavior, regarding idea exploration, near half of studied staff nurses $(48.7 \%)$ reported that they usually recognize opportunities to make a positive difference in work, department, hospital or with client. In relation to idea generation, about half of staff nurses $(51.3 \%)$ reported that they always generate original solutions to problems. Regarding idea championing, more than half of staff nurses $(56.6 \%)$ reported that they always generate attempts to convince supervisors to support an innovative idea. In relation to idea implementation, about two thirds of staff nurses (63.2\%) reported that they always systematically introduce innovative ideas into work practices. Table 6 , clearly shows that the staff nurses reported high mean scores in all dimension of innovative work behavior. The highest mean score $(8.46 \pm 1.91,12.30 \pm 2.76)$ were for idea championing and idea implementation respectively.

7. Figure 2, shows that half of staff nurses $(50 \%)$ had high innovative work behavior.

8. Table 7: shows a significant correlation between staff nurses innovative work behavior and perception toward organizational culture. Also the core values, coordination\& integration, customer focus, organizational learning, and vision as an organizational culture elements significantly correlated with nurses innovative behavior.

Table 1. Agreements of the staff nurses regarding empowerment as categories of organization culture (no $=76)$.

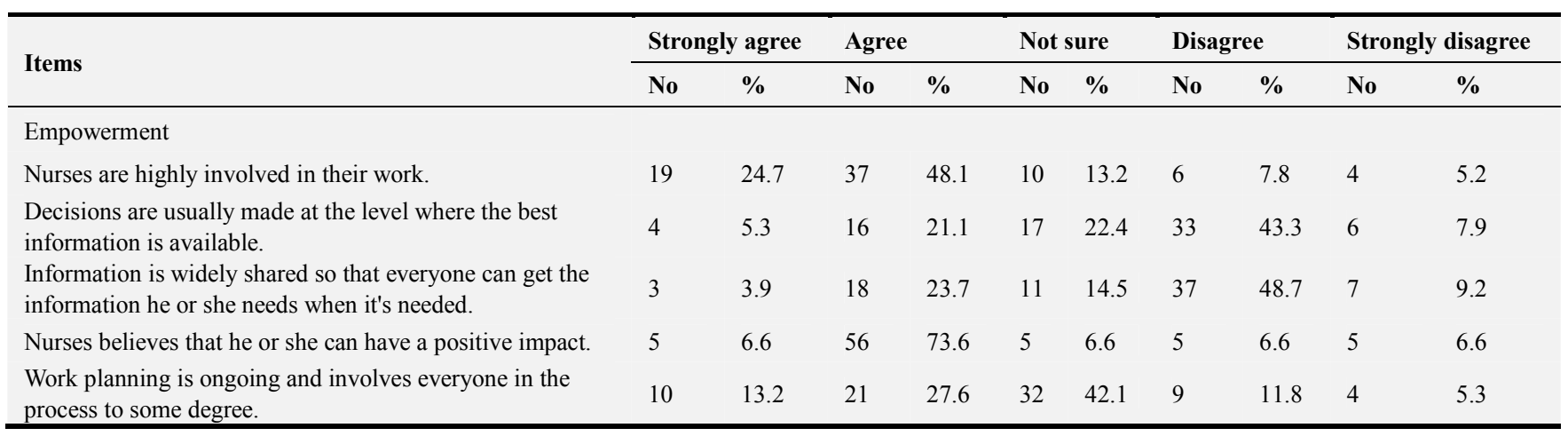


Table 2. Agreements of the staff nurses regarding creating change as categories of organization culture (no=76).

\begin{tabular}{|c|c|c|c|c|c|c|c|c|c|c|}
\hline \multirow{2}{*}{ Items } & \multicolumn{2}{|c|}{ Strongly agree } & \multicolumn{2}{|c|}{ Agree } & \multicolumn{2}{|c|}{ Not sure } & \multicolumn{2}{|c|}{ Disagree } & \multicolumn{2}{|c|}{ Strongly disagree } \\
\hline & No & $\%$ & No & $\%$ & No & $\%$ & No & $\%$ & No & $\%$ \\
\hline \multicolumn{11}{|l|}{ Creating change } \\
\hline $\begin{array}{l}\text { Nurses respond well to competitors and other changes in the work } \\
\text { environment. }\end{array}$ & 10 & 13.2 & 5 & 6.6 & 5 & 6.6 & 48 & 63.2 & 8 & 10.4 \\
\hline New and improved ways to do work are continually adopted. & 4 & 5.3 & 15 & 19.7 & 45 & 59.2 & 10 & 13.2 & 2 & 2.6 \\
\hline Attempts to create change seldom meet with resistance. & 4 & 5.3 & 19 & 24.9 & 40 & 52.6 & 9 & 11.9 & 4 & 5.3 \\
\hline Different parts of the organization often cooperate to create change. & 10 & 13.2 & 5 & 6.6 & 16 & 21.0 & 36 & 47.4 & 9 & 11.8 \\
\hline
\end{tabular}

Table 3. Agreements of the staff nurses regarding organizational learning as categories of organization culture.

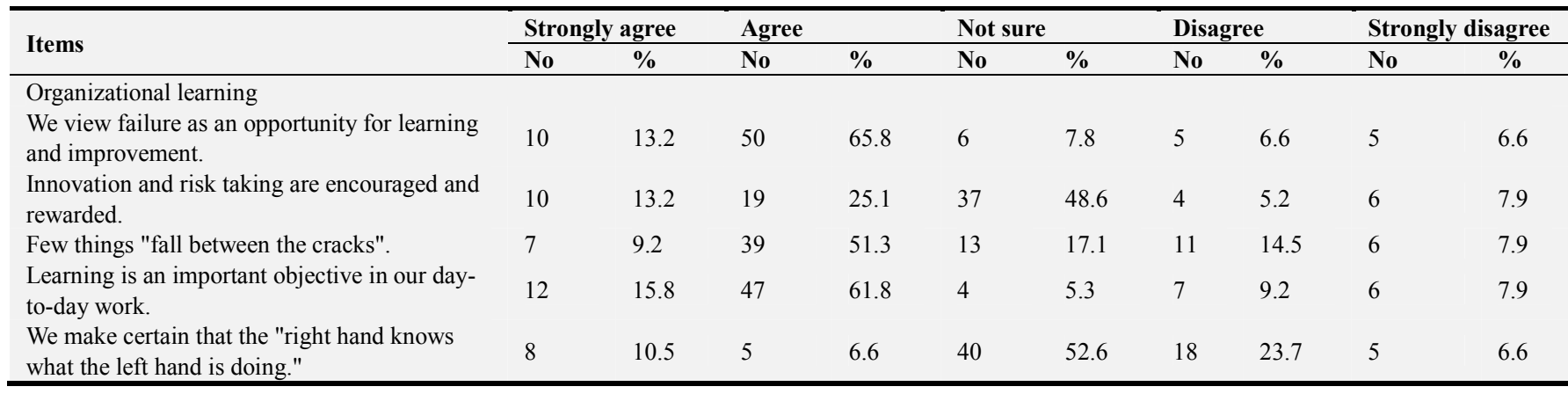

Table 4. Ean scores of staff nurses perception regarding organizational culture.

\begin{tabular}{|c|c|c|}
\hline Items & Max score & $\mathbf{X} \pm \mathbf{S D}$ \\
\hline Empowerment. & 25 & $16.77 \pm 2.98$ \\
\hline Team orientation. & 25 & $16.03 \pm 2.55$ \\
\hline Capability development. & 25 & $15.05 \pm 2.62$ \\
\hline Core values. & 25 & $15.35 \pm 2.84$ \\
\hline Agreements. & 25 & $17.85 \pm 3.19$ \\
\hline Creating change & 25 & $12.10 \pm 3.26$ \\
\hline Patient focus. & 25 & $15.90 \pm 2.39$ \\
\hline Organizational learning. & 25 & $19.15 \pm 2.51$ \\
\hline Strategic direction. & 25 & $16.67 \pm 2.45$ \\
\hline Goals \& objectives. & 25 & $14.42 \pm 2.58$ \\
\hline Vision. & 25 & $15.43 \pm 2.99$ \\
\hline
\end{tabular}

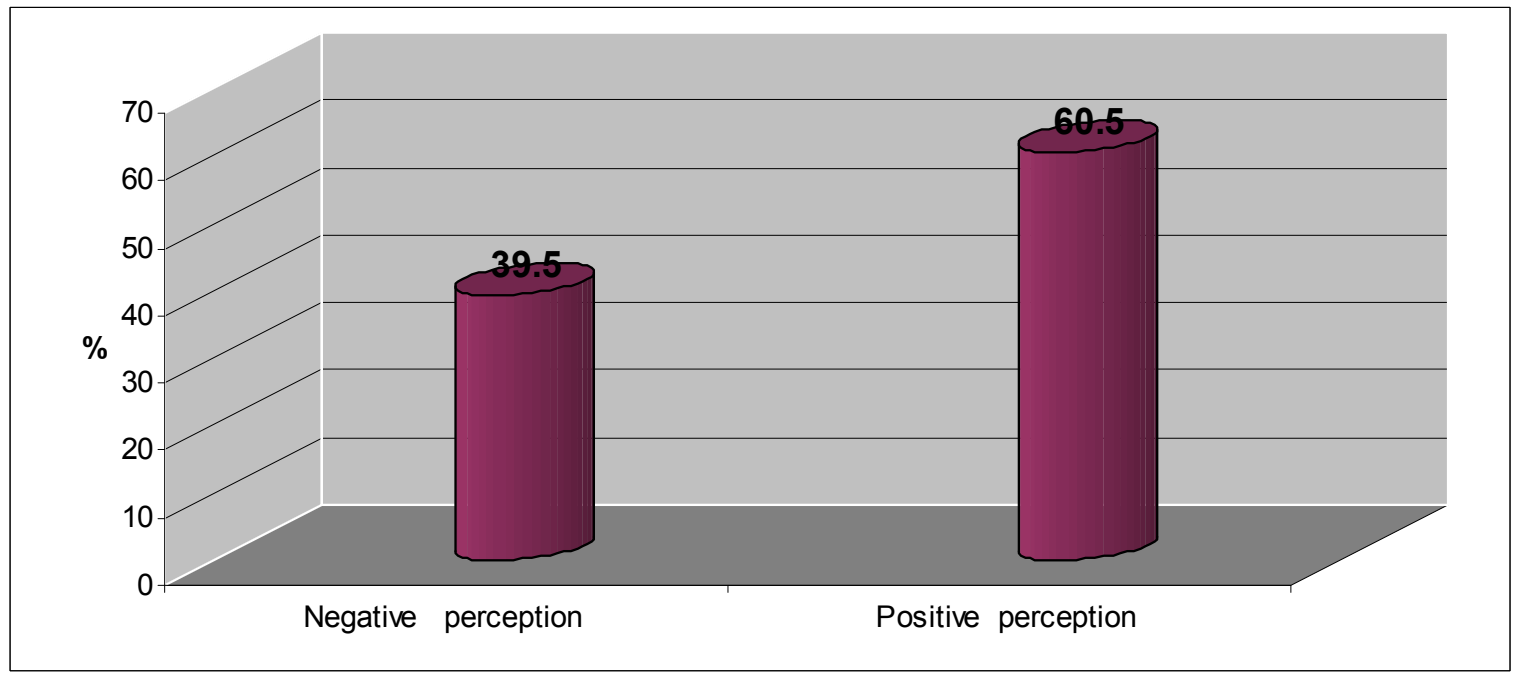

Figure 1. Percentages distribution of staff nurses perception regarding organizational culture. 
Table 5. Distribution of the staff nurses agreements regarding innovative work behavior.

\begin{tabular}{|c|c|c|c|c|c|c|c|c|c|c|c|c|}
\hline \multirow{2}{*}{ Items } & \multicolumn{2}{|c|}{ Always } & \multicolumn{2}{|c|}{ Usually } & \multicolumn{2}{|c|}{ sometimes } & \multicolumn{2}{|c|}{ Rarely } & \multicolumn{2}{|c|}{ Never } & \multicolumn{2}{|c|}{ Total } \\
\hline & No & $\%$ & No & $\%$ & No & $\%$ & No & $\%$ & No & $\%$ & No & $\%$ \\
\hline \multicolumn{13}{|l|}{ Idea exploration. } \\
\hline $\begin{array}{l}\text { Look for opportunities to improve an existing nursing service } \\
\text { or work relationship. }\end{array}$ & 30 & 39.5 & 25 & 32.9 & 6 & 7.8 & 10 & 13.2 & 5 & 6.6 & 76 & 100 \\
\hline $\begin{array}{l}\text { Recognize opportunities to make a positive difference in work, } \\
\text { department, hospital or with client. } \\
\text { Idea generation. }\end{array}$ & 18 & 23.7 & 37 & 48.7 & 8 & 10.5 & 8 & 10.5 & 5 & 6.6 & 76 & 100 \\
\hline Generate original solutions to problems & 39 & 51.3 & 19 & 25.0 & 8 & 10.5 & 5 & 6.6 & 5 & 6.6 & 76 & 100 \\
\hline \multicolumn{13}{|l|}{ Idea championing. } \\
\hline $\begin{array}{l}\text { Encourage key organization members to be enthusiastic about } \\
\text { innovative ideas. }\end{array}$ & 40 & 52.7 & 22 & 28.9 & 6 & 7.9 & 3 & 3.9 & 5 & 6.6 & 76 & 100 \\
\hline $\begin{array}{l}\text { Attempts to convince supervisors to support an innovative } \\
\text { idea. } \\
\text { Idea implementation. }\end{array}$ & 43 & 56.6 & 19 & 25.1 & 9 & 11.8 & 3 & 3.9 & 2 & 2.6 & 76 & 100 \\
\hline
\end{tabular}

Table 6. Mean scores of the staff nurses regarding innovative work behavior.

\begin{tabular}{lll}
\hline Items & Max score & X \pm SD \\
\hline Idea exploration. & 15 & $11.36 \pm 2.20$ \\
Idea generation. & 15 & $12.00 \pm 2.64$ \\
Idea championing. & 10 & $8.46 \pm 1.91$ \\
Idea implementation. & 15 & $12.30 \pm 2.76$ \\
Total & 55 & $44.13 \pm 5.65$ \\
\hline
\end{tabular}

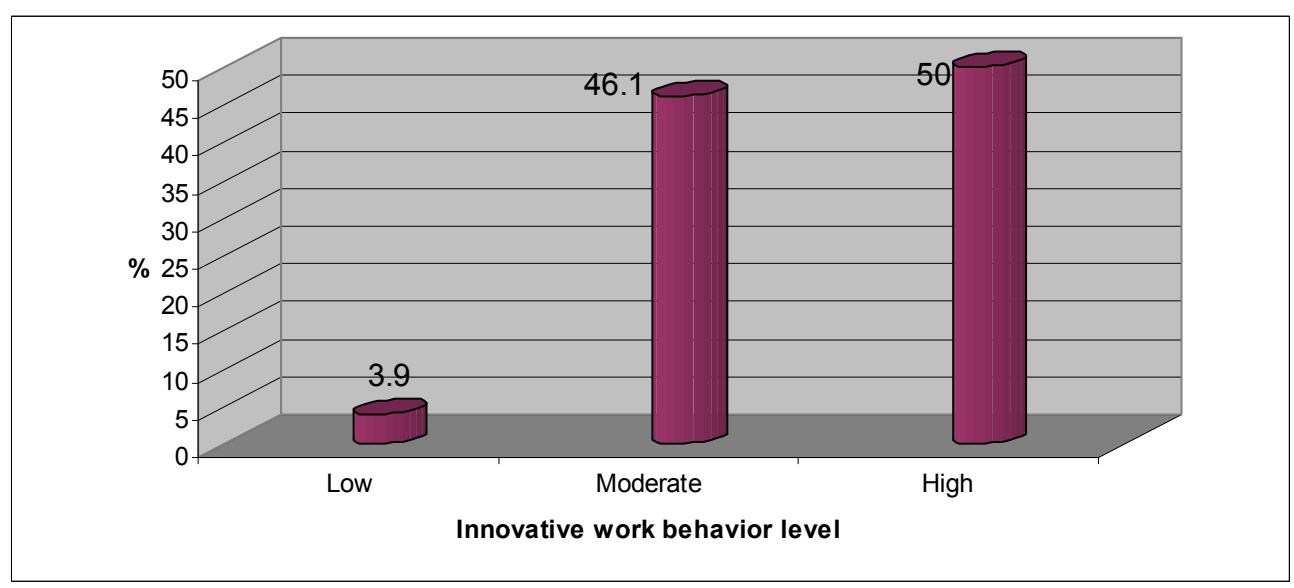

Figure 2. Distribution of the staff nurses regarding innovative work behavior level.

Table 7. Correlation between staff nurses' perception toward organizational culture and innovative work behavior.

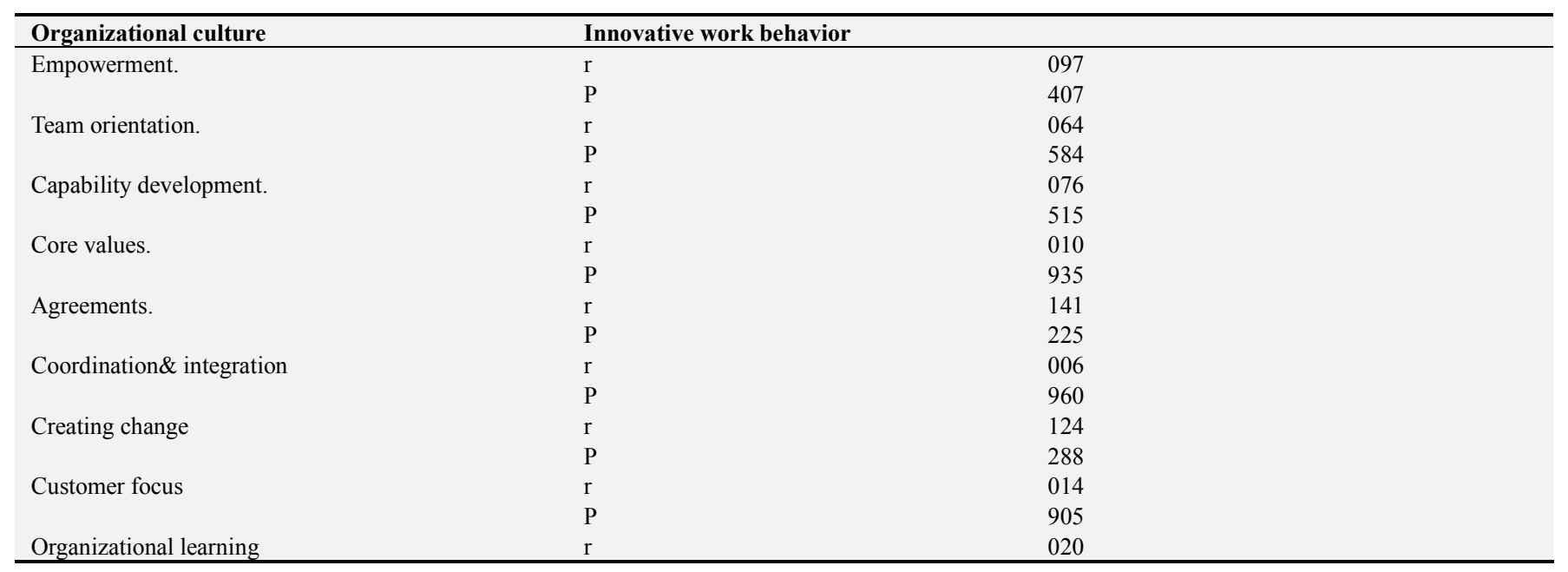




\begin{tabular}{lll}
\hline Organizational culture & Innovative work behavior & \\
\hline \multirow{3}{*}{ Strategic direction } & $\mathrm{P}$ & 862 \\
& $\mathrm{r}$ & 158 \\
Goals\& objectives & $\mathrm{P}$ & 173 \\
& $\mathrm{r}$ & 071 \\
Vision & $\mathrm{P}$ & 545 \\
& $\mathrm{r}$ & 030 \\
Total of organizational culture & $\mathrm{P}$ & 796 \\
& $\mathrm{r}$ & 839 \\
\hline
\end{tabular}

\section{Discussion}

The nurses spend more of their hours at workplace; their organization's culture affects both their work lives as well as their personal lives. Organizational culture refers to the beliefs, ideologies, principles and values that the individuals of an organization share. This culture is a determining factor in the success of the organization. Organizational culture has the potential to enhance organizational performance, job satisfaction, and enhance the sense of certainty about problem solving. If an organizational culture becomes incongruent with the changing expectations of internal and/or external stakeholders, the organization's effectiveness can decline [18].

In the present rapid changing environment, organizations are facing greater challenges, and they need to promote innovative behaviors to create and deliver their products and services, to stay competitive, and lead the change process itself. In order to accomplish their task successfully, organizations render support to their employees to innovate their process, methods, and operations [13].

Regarding empowerment as elements of organizational culture, the result of present study illustrated that the highest percentage of studied staff nurses agreement on nurse believes that he or she can have a positive impact. The result of present study consistent with Lundy, (2014) who stated that nursing encompasses autonomous and collaborative care of individuals of all ages, families, groups and communities sick or well and in all settings [19]. This may be due to the nurses are the major assets of the hospital with different specializations, educational qualifications and work experiences that contribute effectively within successful organization. So, the nurses have trust about their effective role in the hospital.

In relation to creating change as elements of organizational culture, the result of present study showed that more than half of studied staff nurses not sure about new and improved ways to do work are continually adopted and attempts to create change seldom meet with resistance. This finding is consistent with Spetz, Burgess \& Phibbs, (2012) who conducted study about "what determines successful implementation of inpatient information technology systems?". They stated that the challenging of managing change in health care facilities and new technologies often incite resistance from nurses who already cannot find enough time to complete patient tasks in their shift. Also, they find lack of cooperation among staff, fear of using new technique appear when implementing a change in procedure [20].

The result of present study is disagreed with Bharthvajan, (2014) who conducted study about "organizational culture and climate". He stated that the employees show a strong resistance to the change in policies or procedures but technological changes easily accepted because they improve the working conditions of the employees and make them able to work with less strain and it would be more compatible and flexible for an employee to understand [21].

Regarding organizational learning as an element of organizational culture, the result of present study revealed that highest percentage of studied staff nurses agreement was related to nurses view failure as an opportunity for learning and improvement and learning is an important objective in their day-to-day work.

The finding of the current study is agreed with Taylor, Lillis, Iyann, (2015) who stated that educational preparation for nurses, and lifelong learning has become a major issue of nursing to enhance health care services and nurses themselves [22]. Also, the present study result was consistent with Catheirne, (2011) who conducted study about "continuing education a personal responsibility". He stated that the learning for nurses enhance the quality of patients care that receive from nurse, and enhance service delivery. Also, it help nurse to direct his/ her career and cover gaps in skills and capabilities [23]. This may be due to nurses need scientific knowledge to improve decision-making and skills regarding the patients care and how to implement it for achieving a high-quality care for patients and families.

In relation to total mean score of studied staff nurses perception regarding organizational culture. The present study revealed that the highest mean score of studied staff nurses perception was related to organizational learning. While the lowest mean score was related to creating change. Also, more than half of nurses reported their positive perception regarding organizational culture.

The result of the present study was inconsistent with Weeks and Erasmus (2013) who conducted study about "organizational culture \& climate: elusive pieces in the health care technology management puzzle". They indicated that organization glue (connection) records the highest mean score that holds the organization together is loyalty and mutual trust [24].

Regarding idea exploration as elements of innovative work behavior, the present study revealed that near half of studied staff nurses usually recognize opportunities to make a positive difference in work, department, and hospital or with client. 
This reflects what was emphasized by Noor and Dzulkifli (2013) who conducted study about "assessing leadership practices, organizational climate and its effect towards innovative work behavior in R\&D". They found that study participants prioritized making difference in work as an objective for their life and they seek opportunities to it [12]. This is due to the creativity come up with new ideas primarily depends on individuals and partly on the management of an organization. The ability to create innovative solutions is dependent on the knowledge, and even more on the experience of individuals to apply the knowledge to solve the novel problem and generating new ideas.

In relation to idea generation as elements of innovative work behavior, about half of studied staff nurses always generate original solutions to problems. In the same respect Jafri (2010) who conducted study about "organizational commitment and employee's innovative behavior: a study in retail sector". He suggests that knowledge can be used to create new ideas and that these ideas can be used as the building blocks from which to develop and provide excellence in service and/or other effective workplace processes [25].

Regarding idea championing as elements of innovative work behavior, more than half of staff nurses always generate attempts to convince supervisors to support an innovative idea. This result agree with Xerri, (2012) conducted study about' workplace relationships and the innovative behavior of nursing employees: a social exchange perspective". He revealed that nurses perceive low level of organizational support. From researcher' point of view the supervisors not always delegate responsibilities to nurses, not recognize or support their innovative efforts, or provide them with the resources needed to innovate and consult them in the decision making process to enhance the innovative work behavior among nurses [26].

In the same respect Gassmann and Morhart, (2012) were conducted study about "innovative work behavior: the roles of employee expectations and effects on job performance". They reported that organizational support for innovation is a salient organizational factor that provides important contextual information for innovative self-efficacy judgments. They added that in a work environment where innovation is encouraged and valued throughout the whole organization, employees' innovative self-efficacy beliefs are enhanced through observing people that successfully engage in innovative work behavior [27].

In relation to idea implementation as elements of innovative work behavior, the present study revealed that about two thirds of staff nurses always systematically introduce innovative ideas into work practices. The present study result was in-line with Carmeli, Meitar \& Weisberg, (2006) conducted study about " self-leadership skills and innovative behavior at work". They described innovative behavior as a the process of bringing new problem solving and transfer ideas into use, thereby enhancing service or process. Innovative behavior in the workplace begins by an employee identifying a work-based problem. This is followed by the development of new ideas and solutions for the problem/s. They added, the final step in the innovative process is to develop support for the new ideas and solutions, so they become embedded within the organization. This may be related to nurses at critical care units usually dealing with patients who require complex assessments and interventions this enhance their ability to think critically and introduce innovative solutions [28].

The present study revealed that, half of staff nurses had high innovative work behavior. This result is supported by AACN (2015) who pointed that nurses work in critical areas are creative, support lifelong learning, search for information anywhere, and long run become more innovative [9]. Also, it consistent with Stoffers, Neessen and Dorp, (2015) who conducted study about "organizational culture and innovative work behavior: a case study of a manufacturer of packaging machines". They reported that the employees valued innovative work behavior higher in the preferred status than in the current status [29].

The result of the present study showed a significant correlation between staff nurses perception to their organizational culture and their innovative work behavior. In this respect Stoffers, Neessen and Dorp, (2015) revealed that there was a significant correlation between market culture and innovative work behavior. From researcher point of view organizational culture elements can affect on the nurses behaviors by positive or negative, a strong organizational culture would clearly influence the way of nurses behave and act [29].

The result of the present study also showed a significant correlation between organizational culture elements (core values, coordination\& integration, customer focus, organizational learning) and vision as with nurse's innovative behavior. This result was consistent with Zamini and Barzegary, (2011) who conducted study about" the relationship between organizational culture and job burnout among the professors and employees in the University of Tabriz, Procedia" [30]. Also, the study result was supported by Sashkin and Rosenbach (2013) who conducted study about "organizational culture assessment". They reported that clear values, vision and objectives are important segments in shaping employee innovative behavior [31]. Also, Dul and Ceylan (2010) who conducted study about" work environments for employee creativity Rotterdam school of management, Erasmus University". They reported that work environments for employee is creative [15].

In the same line Rana and Han (2015) conducted study about "effect of organizational culture on nurses' turnover intention: the mediating effect of workplace bullying and work burnout". They emphasized that organization which support learning and prioritized it as a main objective, help its employees to develop challenging, creativity, and innovative behavior [32]. In the same respect Wang et al., (2010) conducted study about" the critical role of culture when you really want to innovate". They reported that the culture has a profound impact on the innovation of an 
organization. Also, they revealed a strong positive relationship between customer focus, participative management practices, coordination inter and intra departments and innovative culture in organization [16].

\section{Conclusion}

The results of this study can be summarized as follows; more than half of nurses had positive perception regarding their organizational cultures, half of nurses had high innovative work behavior and there was a significant correlation between nurses perception regarding organization culture and their innovative work behavior. This study is significant to provide basic data that can be used by nursing managers to develop an environment that fosters the innovative behavior of nurses.

\section{Recommendation}

The nurse supervisor integrate his role with support of top management to:

1. Enhance nurses organizational learning through designated in-service educational programs.

2. Be open to suggestions of nurses, give nurses the responsibility to solve problems by themselves, and improve the relationship between the nurses and their supervisors

3. React positively to the innovative efforts of production nurses by provide nurses the time and resources to carry out innovative efforts

4. Support innovation as a job requirement

5. Reduce nurses resistance to change through communicating the objectives, methods and process of introducing new changes and technologies.

6. Further research, can be conducted to identify the factors that enhance innovative work behavior across cultures.

\section{References}

[1] Balthazard, P. A., Cooke, R. A., \& Potter, R. E. (2012). Dysfunctional Culture, Dysfunctional Organization: Capturing the Behavioral Norms that Form Organizational Culture \& Drive Performance. Journal of Managerial Psychology, 21 (8): 709-732.

[2] Hofsted, G., \& Bond, M. H., (2012). Impact of Organizational Culture on Organizational Performance Interdisciplinary Journal of contemporary Research in Business, 3 (9): 5-20.

[3] Darlene, F., (2009). The Relationship Between A Performance \& Its Leadership, \& The Impact On Employee Performance \& Satisfaction American Psychological Association, 5th ed: 2040 .

[4] Cameron, K. S., \& Quinn, R. E., (2011). Diagnosing \& Changing Organizational Culture: the Competing Values Framework. Reading, MA: Addison-Wesley: 25-40.

[5] Denison, D. R., (2011). Organizational Culture Survey. UNT
Health science center. 1 (4): 1-10.

[6] Yang, H., and Huang, F. (2010) Perceived Organizational Culture, Professional Commitment, Advice Network and Job Satisfaction of Novice Nurses. Wseas Transactions on Communications. 9 (9): 595-904.

[7] McKenna, E., (2012). Business Psychology \& Organizational Behaviors New York, Psychology Press 5th ed: 10-25.

[8] Patterson, F., Kerrin, M., Gatto-Roissard, G. and Coan, P. (2009). Everyday Innovation: How to Enhance Innovative Working in Employees and Organizations. NESTA, London.

[9] American Association of Critical Care Nurses (AACN) (2015). Scope and standards for acute and critical care nursing practice, An AACN Critical Care Publication, Columbia. 7-31.

[10] Creswick, N. and Hains, I. (2011). Innovation in Intensive Care Nursing Work Practices With Pacs. European federation for medical informatics. User Centered Networked Health Care. 402- 406 .

[11] Yeun, Y. (2014). Job stress, Burnout, Nursing Organizational Culture and Turnover intention among nurses. J. Korea Acad. Industr. Coop. Soc. 15 (8), 4981-4986.

[12] Noor and Dzulkifli. (2013). Assessing Leadership Practices, Organizational Climate and Its Effect towards Innovative Work Behavior in R\&D. International Journal of Social Science and Humanity, 3 (2). 30-35.

[13] Chombunchoo, N. (2016). The Competency and Innovative Work Behavior of Rajchapat University in Thailand. MiddleEast Journal of Scientific Research 24 (5): 1594-1599.

[14] Dorner. N. (2012). Innovative Work Behavior: The Roles of Employee Expectations and Effects on Job Performance. Doctoral dissertation of the University of St. Gallen, School of Management.20-80.

[15] Dul, J., and Ceylan, C. (2010). Work environments for employee creativity. Rotterdam School of Management, Erasmus University. 2-4.

[16] Wang, S., Guidice, R. M., Tansky, J. W., \& Wang, Z., (2010). The critical role of culture when you really want to innovate. Human Resource Management, 49 (4): 767-792.

[17] De Jong, J. (2007). Individual innovation: The connection between leadership and employees' innovative work behavior. PhD University of Twente, EIM: Zoetermeer.

[18] Kayla, L., \& Dem, M., (2015) The Importance of Culture in Organizations Hearst Newspapers LLC.

[19] Lundy, K. S. (2014). A History Of Health Care And Nursing In Master, Role Of Development In Professional Nursing Practice $3^{\text {rd }}$ ed. Burlington, Jones \& Bartlett learning.11-12.

[20] Spetz, J., Burgess, J. F., \& Phibbs, C. S. (2012). What Determines Successful Implementation Of Inpatient Information Technology Systems? The American Journal of Managed Care, 18 (3), 157-162.

[21] Bharthvajan, R., (2014). Organizational Culture \& Climate International Journal of Innovative Research in Science, Engineering \& Technology, 3 (1): 870-880.

[22] Taylor, C., Lillis, C., Iyann, P., (2015). Fundamental of Nursing - the Art and Person Centered Nursing Care, 8ed London: Scutari Press105-110. 
[23] Catherine, W., (2011). Continuing Education A Personal Responsibility Advance in Neonate Care, 11 (4): 227-228.

[24] Weeks R. V \& Erasmus L. D. (2013). Organizational Culture \& Climate: Elusive Pieces in the Health Care Technology Management Puzzle. Journal of Contemporary Management, $10(2): 39-58$.

[25] Jafri, M (2010). Organizational Commitment and Employee's Innovative Behavior: A Study in Retail Sector. Journal of Management Research, 10 (1): 62-68.

[26] Xerri, M. J. (2012). 'Workplace Relationships And The Innovative Behavior of Nursing Employees: A Social Exchange Perspective', Asia Pacific Journal of Human Resources, 51 (1): 103-123.

[27] Gassmann, O. and Morhart, F. (2012). Innovative Work Behavior: The Roles of Employee Expectations and Effects on Job Performance. Dissertation. Doctor of Philosophy in Management. University of St. Gallen, School of Management, Economics, Law, Social Sciences and International Affairs.
[28] Carmeli, A, Meitar, R, \& Weisberg, J. (2006). Self-Leadership Skills and Innovative Behaviour At Work. International Journal of manpower, 27 (1): 75-90.

[29] Stoffers J., Neessen P., Dorp P., (2015). Organizational Culture and Innovative Work Behavior: A Case Study of a Manufacturer of Packaging Machines. American Journal of Industrial and Business Management, 5, 198-207.

[30] Zamini, S. and Barzegary, L. (2011). The Relationship Between Organizational Culture And Job Burnout Among The Professors And Employees In The University of Tabriz. Procedia - Social and Behavioral Sciences 4-1968.

[31] Sashkin, M., and Rosenbach, W. (2013). Organizational Culture Assessment Questionnaire. International and Pan American Copyright Conventions. 1-12.

[32] Ran, Y., and Han, J. (2015). Effect of Organizational Culture on Nurses' Turnover Intention: The Mediating Effect of Workplace Bullying and Work Burnout Advanced Science and Technology Letters Vol.120. 125-128. 